\title{
When Power Makes Others Speechless: The Negative Impact of Leader Power on Team Performance
}

\section{Citation}

Tost, Leigh Plunkett, Francesca Gino, and Richard P. Larrick. "When Power Makes Others Speechless: The Negative Impact of Leader Power on Team Performance." Academy of Management Journal (forthcoming).

\section{Permanent link}

http://nrs.harvard.edu/urn-3:HUL.InstRepos:10996804

\section{Terms of Use}

This article was downloaded from Harvard University's DASH repository, and is made available under the terms and conditions applicable to Open Access Policy Articles, as set forth at http:// nrs.harvard.edu/urn-3:HUL.InstRepos:dash.current.terms-of-use\#OAP

\section{Share Your Story}

The Harvard community has made this article openly available. Please share how this access benefits you. Submit a story.

Accessibility 
Running Head: LEADER POWER AND TEAM PERFORMANCE

When Power Makes Others Speechless:

The Negative Impact of Leader Power on Team Performance

\author{
Leigh Plunkett Tost \\ University of Michigan \\ Francesca Gino \\ Harvard University \\ Richard P. Larrick \\ Duke University
}

Forthcoming, Academy of Management Journal

Author Note

The authors greatly appreciate the support and facilities of the Center for Leadership and Strategic Thinking at the University of Washington and the Center for Decision Research at the University of North Carolina at Chapel Hill. Please address correspondence to lptost@umich.edu. 


\begin{abstract}
We examine the impact of the subjective experience of power on leadership dynamics and team performance and find that the psychological effect of power on formal leaders spills over to affect team performance. We argue that a formal leader's experience of heightened power produces verbal dominance, which reduces team communication and consequently diminishes performance. Importantly, because these dynamics rely on the acquiescence of other team members to the leader's dominant behavior, the effects only emerge when the leader holds a formal leadership position. Three studies find consistent support for this argument. The implications for theory and practice are discussed.
\end{abstract}

Key words: Power; Leadership; Authority; Teams; Communication; Talking; Dominance; Team Performance; Learning; Consent; Legitimacy 


\section{When Power Makes Others Speechless:}

\section{The Negative Impact of Leader Power on Team Performance}

Organizations make extensive use of teams when structuring and allocating work projects. Given the increasing prevalence of teams in modern organizations and the complexities involved in group dynamics, questions about how to ensure high levels of collective learning and effective decision making, along with other key determinants of team performance, have captured extensive attention from researchers and practitioners alike (Martin \& Bal, 2006). One important area of inquiry into team effectiveness is the issue of how the degree of hierarchy within a team can affect team performance. This question is relatively understudied, but some extant literature suggests that steeper hierarchy has a diminishing effect on team learning and team performance in general. For example, in a qualitative field study, Edmondson (2002) found power differences in teams to be negatively associated with team learning, and Eisenhardt and Bourgeois (1988), using a case-based methodological approach, found that power inequality in teams increases political conflict and diminishes team performance. Similarly, other field-based research has shown that when teams are characterized by steeper hierarchies, team members are less likely to learn from member differences (Bunderson, 2003a, 2003b). The negative effect of hierarchy on team performance suggested by these field-based studies may be surprising in light of evidence of the many positive effects of hierarchy: In particular, working in a hierarchical setting can be motivating for some individuals, and hierarchy also has been shown to increase coordination and cooperation (see Anderson \& Brown, 2010, and Halevy, Chou, \& Galinsky, 2011 for recent reviews). Given the multiple benefits of hierarchical contexts, why have previous field-based findings demonstrated a negative effect of power differences on team learning and performance? 
An answer to this question requires an investigation of the micro-mechanisms by which hierarchy can affect leadership dynamics and team performance. In this paper, we argue that to explain the negative effect that power inequalities can have on team performance, it is necessary to look within teams to understand how power differences affect team interactions and decisionmaking processes. We therefore set out to investigate, through a series of laboratory studies, how a team leader's experience of power and level of formal authority affect communication dynamics within the team, team learning, and, ultimately, team performance.

Power, leadership, and formal authority — the focal constructs of this paper — are closely related. Power refers to an individual's relative ability to control others' outcomes, experiences, or behaviors (Keltner, Gruenfeld, \& Anderson, 2003; Thibaut \& Kelley, 1959). Leadership refers to the process of influencing others to pursue group goals (Bass, 2008; Hogg, 2001; Stogdill, 1950). Formal authority refers to the holding of a specific role or office associated with a social hierarchy (Peabody, 1962). Because power is generally viewed as an important basis of influence (French \& Raven, 1959; Lord, 1977), these definitions seem to imply that the concentration of power in a particular leader (whether in a formal position of authority or not) ${ }^{1}$ would enhance the ability of that leader to foster high levels of team performance. Specifically, the greater the leader's power, the more likely he or she is to be able to use that power to elicit desired behaviors from followers. This expectation is consistent with functionalist accounts of the role of power on team and organizational performance, which predict a positive effect of hierarchy on performance (Anderson \& Brown, 2010). From this perspective, greater leader power increases leader effectiveness and, consequently, team performance.

\footnotetext{
${ }^{1}$ Throughout this paper, we use the term "leader" to refer to any individual attempting to influence the group. We use the terms "formal leader" and "leader in a position of authority" to refer to an individual who has received an official title that involves expectations of leadership, such as "manager," "leader," or "director."
} 
However, as evidenced by the field-based findings described above, there are at least two reasons to suspect that this positive relationship between leader power and team performance may not materialize as often as a functionalist account would predict. First, team processes and outcomes are emergent (Marks, Mathieu, \& Zaccaro, 2001). That is, they are not pre-existing entities inherent to the team that are simply waiting to be brought forth by the demands of a powerful leader. Instead, much of the performance that organizations expect of their members is developed through dynamic processes of team interaction (Marks et al., 2001). Team processes can produce ideas that did not exist prior to the team's interactions (De Dreu \& West, 2001; Mathieu, Heffner, Goodwin, Salas, \& Cannon-Bowers, 2000). In tasks that require creative problem solving, information sharing, and the integration of viewpoints across team members, leaders cannot simply appeal to their power to elicit performance; instead, performance must be cultivated by creating a team context that facilitates high levels of performance (Agrell \& Gustafson, 1996; Anderson \& West, 1998; Drach-Zahavy \& Somech, 2001; West, 1990). As a consequence, team performance is dependent upon a variety of factors that cannot be directly affected by a leader's exercise of power.

Second, the leader is not unaffected by his or her own power. Indeed, a broad stream of social-psychological research differentiates between the exercise of power and the psychological experience of power, which refers to the powerholder's subjective feelings of control over the resources, outcomes, and experiences of others. Subjective feelings of power may diverge from the structural power that one can objectively be demonstrated to hold (Proell \& Sauer, 2011). The experience of power can have wide-ranging effects on the cognitions and behavior of the powerholder, many of which may challenge a leader's ability to effectively facilitate team performance. For example, research has demonstrated that the psychological experience of 
power leads powerholders to objectify others (Gruenfeld, Inesi, Magee, \& Galinsky, 2008), to be less adept at understanding the perspectives of others (Galinsky, Magee, Inesi, \& Gruenfeld, 2006), to be more likely to stereotype others than to see them as individuals (Fiske, 1993; Goodwin, Gubin, Fiske, \& Yzerbyt, 2000; Goodwin, Operario, \& Fiske, 1998), and to be less likely to listen to others (See, Morrison, Rothman, \& Soll, 2011).

The integration of these two points implies that the concentration of power in a team leader may not have the straightforward and positive effects on team coordination and collaboration that would be expected in a strictly functionalist account of the effects of hierarchy. In particular, we argue that the psychological experience of power by leaders may influence their behavior toward other team members in ways that could threaten a critical determinant of team success: the open exchange of information within the team. Team communication plays a crucial role in facilitating high levels of team performance (Dionne, et al., 2004; Gardner, Gino, \& Staats, 2012; Smith et al., 1994). However, we argue that when a formal leader experiences a heightened subjective sense of power, he or she tends to dominate group discussions and interactions, which leads other team members to perceive that their views and perspectives are not valued. Consequently, communication and information sharing in the team is limited, and performance is diminished.

However, we contend that this dynamic is dependent upon other team members' tendencies to acquiesce to the leader's dominant behavior. We argue that team members are only inclined to do so when the leader in question holds a formal position of authority. When the leader does not hold a formal position of authority, his or her psychological experience of power is less likely to negatively affect the team's performance, because the other team members will not defer to the leader's dominance. Thus, we argue that the nature of the team-level impact of a 
leader's subjective experience of power depends on whether the leader holds a formal position of authority that is recognized by team members.

We aim to make three central contributions to organizational research. First, by highlighting the critical role of the leader's subjective experience of power in diminishing perceptions of leader openness and open communication within the team, we answer calls to identify and explain the micro-processes by which power hierarchies can negatively affect team learning and performance (e.g., Van der Vegt, de Jong, Bunderson, \& Molleman, 2010). Second, we highlight the subjective sense of power as an important variable in organizational studies. The subjective experience of power is distinct from the structural forms of power often examined in organizational research, but our theorizing and empirical findings indicate that the effects of feelings of power, when experienced by an individual in an authority position, go beyond the individual level to affect the perceptions and behaviors of the entire team. Third, we contribute to the burgeoning literature on the important role of followers in the leadership process (e.g., DeRue, 2011; Dvir \& Shamir, 2003; Grant et al., 2010; Howell \& Shamir, 2005) by highlighting the critical role of other team members' reactions to a leader's behavior and demonstrating that the leader's formal authority moderates these reactions. Specifically, our research demonstrates that, because of the crucial role of team members' reactions, leaders' power-prompted dominance behaviors are more likely to negatively affect the team's performance if the leader has the legitimacy afforded by holding a formal position of authority.

\section{LEADER POWER AND TEAM PERFORMANCE}

Open communication within teams is a crucial determinant of team performance (Dionne, et al., 2004; Gardner et al., 2012; Guzzo \& Dickson, 1996), affecting team productivity (Pearson, 1991), cooperation (Orbell, van de Kragt, \& Dawes, 1988), and innovation (Catmull, 2008; 
Edmondson, 2003). Drawing on social-psychological research on the effects of power on the powerholder, as well as on research from political science and sociology on the importance of consent in power dynamics, we propose that a formal leader's subjective sense of power has detrimental effects on team performance by decreasing the openness of communication within the team.

Building on social-psychological research, we suggest two main ways in which the subjective experience of power influences how an individual engages in leadership in team settings. First, the psychological experience of power leads individuals to be more inclined to express their attitudes and opinions in group contexts (Anderson \& Berdahl, 2002; Berdahl \& Martorana, 2006). Second, individuals who experience increased feelings of power come to devalue the perspectives, opinions, and contributions of others (Georgesen \& Harris, 1998; Kipnis, 1972). Individuals who are prone to express their attitudes and opinions, and who feel that their perspectives are more valuable than the perspectives of others, are likely to feel entitled to dominate interpersonal interactions. We therefore expect that leaders with a high subjective sense of power are likely to feel entitled to verbally dominate team interactions. Thus, we predict the following:

Hypothesis 1: Formal leaders with a high subjective sense of power will spend more time talking in team meetings than will formal leaders with a neutral subjective sense of power.

This notion is consistent with the classic work of Bales and colleagues, who found that early talking in group interactions establishes an individual as a dominant group member and that this early dominance tends to perpetuate the individual's verbal dominance throughout the life of the group (Bales, Strodtbeck, Mills, \& Roseborough, 1951). As a consequence, Bales and 
colleagues (1951) found that individuals who engage in early dominant behavior continue to talk more frequently than individuals who are not dominant in early interactions. Bales' work focused primarily on how personality characteristics predict who will engage in verbal dominance. In contrast, our research focuses on how an individual's subjective experience of power, which can be altered at any time by the social context, prompts these behaviors. In addition, most other previous research on talking in teams has focused on how formal authority is associated with increased talking (see Stein \& Heller, 1979 for a review) rather than on how an individual's sense of power affects these behaviors.

Thus, we expect that when an individual experiences a high subjective sense of power, he or she is likely to attempt to verbally dominate social interactions. We further expect that when this individual is a formal team leader, the leader's verbal dominance will be detrimental to team communication. Just as open communication is critical for team effectiveness (Catmull, 2008; Dionne, et al., 2004; Edmondson, 2003; Gardner et al., 2012; Guzzo \& Dickson, 1996), the openness exhibited by the team's formal leader is critical for producing open communication within a team. Perceptions of the openness of team communications has been defined both at the level of team members' perceptions of the team's formal leader (previously referred to as "leader openness," here termed "authority openness") and at the level of team members' perceptions of the team as a whole (team open communication). Authority openness refers to the extent to which team members feel that the team's formal leader listens to them, is interested in their perspectives, and considers their ideas (Ashford, Rothbard, Piderit, \& Dutton, 1998; Detert \& Burris, 2007). Team open communication refers to the extent to which team members feel that the team as a whole tends to listen to each member's ideas and encourages and facilitates input from all team members (Barry \& Stewart, 1997). 
When a formal leader verbally dominates a team interaction, the leader signals to others in the team that their perspectives are not valued. Consequently, the dominating behavior elicited by a high subjective sense of power is likely to reduce perceptions of authority openness and diminish open communication within the team. We thus expect the following:

Hypothesis 2: Teams whose formal leader experiences a high subjective sense of power will report lower levels of communication openness (i.e., authority openness and open communication) than will teams whose formal leader experiences a neutral subjective sense of power.

Furthermore, since open communication is critical to team effectiveness (Dionne, et al., 2004; Gardner et al., 2012; Guzzo \& Dickson, 1996), we expect that the negative effect of a formal leader's subjective experience of power on team communication in turn produces a negative effect on team performance. We therefore hypothesize the following:

Hypothesis 3: Teams whose formal leader experiences a high subjective sense of power will exhibit worse performance than will teams whose formal leader experiences a neutral subjective sense of power.

This series of predictions converges on the model depicted in Figure 1. Specifically, we expect that when a formal leader experiences a heightened sense of power, the leader will attempt to verbally dominate team interactions, an effect that will hinder communication openness, which will in turn diminish team performance. We therefore hypothesize the following:

Hypothesis 4: The effect of a formal leader's subjective experience of power on team performance is mediated in sequence by the formal leader's amount of talking and by communication openness. 
Insert Figure 1 about here

We suggest that the hypotheses above apply only to formal leaders. In particular, we argue that these effects cannot emerge without the consent (implicit or otherwise) of other team members. If a high subjective sense of power encourages these behaviors on the part of leaders, it is the leader's formal position that permits the effects to spill over to affect the entire team.

\section{Formal Authority and the Reactions of Team Members}

Sociologists, philosophers, and political scientists have long recognized that a critical component of the successful exercise of power and influence is the consent of those individuals affected by it (e.g., Hamilton \& Biggart, 1985; Locke 1689/1988; see Overbeck, 2010 for a recent, thorough review). A consent-based view of power holds that, because lower-ranking group members are greater in number and can form coalitions, powerholders must acquire their consent and support or else risk being overthrown and losing their power. We suggest that consent also plays an important role in leadership dynamics in teams. Specifically, we have argued that individuals with a high subjective sense of power are likely to attempt to dominate conversations, talking more than other team members. However, they will be able to do so only if other team members permit it — that is, only if other team members yield the floor and do not interrupt the dominating individual. The exercise of verbal dominance thus requires the complicity of other team members.

We suggest that team members are willing to grant this consent to verbal dominance only when their team leader holds a formal leadership position. When someone holds a high-status position, such as a formal leadership role, the position itself affects expectations about that 
individual's behavior in group contexts (Ridgeway \& Berger, 1986). Specifically, individuals in formal leadership positions are expected to talk more as they coordinate group tasks and to exhibit competency and agency in guiding social interactions (Stein \& Heller, 1979). Thus, if a formal leader begins to engage in dominating behavior, other team members are likely to defer to him or her, permitting the verbal dominance as an appropriate and legitimate aspect of this individual's role. However, if someone who is attempting to lead (i.e., to influence the group) in the absence of a formal leadership position begins to engage in dominating behavior, other team members are less likely to acquiesce. This perspective suggests that the predicted positive relationship between leaders' subjective sense of power and their proportion of talking time, as well as the resulting reduction in open communication and team performance, are only likely to emerge when the leader holds a formal position of authority. Specifically, if the negative effects of the leader's experience of power occur because of the increased amount of talking in which powerful leaders engage, and if verbal dominance of conversations requires the consent of others in the team, then these negative effects can only come about when other team members allow it. We therefore expect that the main effects of power predicted in Hypotheses 1 through 3 are moderated by the leader's level of formal authority:

Hypothesis 5: The effect of the leader's subjective experience of power on the leader's amount of talking, the team's level of open communication, and the team's performance emerge only when the leader holds a formal position of authority.

We also expect that the indirect effect predicted in Hypothesis 4 and modeled in Figure 1 is moderated by formal authority. Specifically, we expect that when a leader lacks formal authority, the causal link between power and talking will be broken, eliminating the effect of the leader's 
experience of power on team performance. We therefore propose the following first-stage moderated-mediation hypothesis:

Hypothesis 6: The indirect effect of a leader's subjective experience of power on team performance (as mediated in sequence by the formal leader's amount of talking and by communication openness) is moderated in the first stage by the leader's level of formal authority such that the indirect path is significant only when the leader holds a formal position of authority.

In summarizing the rationale behind Hypotheses 5 and 6, it is important to emphasize that we do not view the negative effect on team performance as being constituted by additive effects of power and authority; that is, it is not that power and authority both produce dominance that, combined, produces even more dominance. Instead, the leader's experience of power affects his or her dominance behavior, and the leader's level of authority affects others' reactions to that behavior (i.e., deference). It is the combination of the leader's behavior (due to power) and other team members' reactions (due to level of authority) that affects the team's interactions and performance.

\section{The Moderating Role of Instrumentality Awareness}

As mentioned earlier, a key reason we expect leaders' subjective experience of power to produce verbal dominance is that feelings of power produce a tendency to devalue the perspectives, opinions, and contributions of others (Georgesen \& Harris, 1998; Kipnis, 1972). However, this tendency is not absolute. Feelings of power are associated with flexibility in the allocation of social attention, depending on the extent to which social targets are instrumental to the achievement of valued goals (Overbeck \& Park, 2006). For example, research has indicated that high-power individuals objectify those around them, paying little attention to those who are 
not relevant to their goal pursuit and greater attention to those who can help them achieve their goals (Gruenfeld, et al., 2008).

Assuming that the formal leader values the team's performance, this line of reasoning suggests that the negative effect of a formal leader's feelings of power on team performance may be eliminated by emphasizing to the leader that team members can make important contributions to the pursuit of team goals and that effective leaders act as facilitators of team performance. When leaders are made aware of others' potential contributions and the importance of leaders' encouragement of those contributions, such that the power-induced bias to devalue others' input is counteracted, they are likely to encourage open communication in the team so that these contributions can be revealed. We refer to team members' capacity to contribute productively to the team's performance as team members' instrumentality. We propose that when leaders perceive team members as instrumental, the effect of power on leader talking is likely to be minimized because leaders will be more likely to encourage contributions from others and more inclined to listen to those contributions rather than dominating the conversation. Consequently, the negative effect of leader power on team open communication is likely to be minimized, thus eliminating the negative effect of leader power on team performance. We therefore predict the following:

Hypothesis 7: The effect of a formal leader's subjective experience of power on the leader's amount of talking, the team's level of open communication, and the team's performance are eliminated when the leader is reminded of the instrumentality of other team members.

Given this, we also expect that the indirect effect predicted in Hypothesis 4 and modeled in Figure 1 is moderated by instrumentality awareness. Specifically, we expect that when a leader is 
reminded of the instrumentality of team members, the causal link between power and talking will be broken, eliminating the effect of the leader's experience of power on team performance. We therefore propose the following first-stage moderated-mediation hypothesis:

Hypothesis 8: The indirect effect of a formal leader's subjective experience of power on team performance (as mediated in sequence by the formal leader's amount of talking and by communication openness) is moderated in the first stage by the leader's awareness of the instrumentality of other team members, such that the indirect path is significant only when the leader is not reminded that others are instrumental to goal achievement.

\section{Overview of the Present Research}

We conducted three studies to test these hypotheses. Our studies involved teams of three, four, or six members participating in team decision-making simulations. All three studies employed tasks that require collaborative problem solving. Study 1 was designed to examine the fundamental premise of our arguments: that a formal leader's experience of power leads to greater amounts of talking in team interactions (Hypothesis 1), which diminishes perceptions of authority openness (Hypothesis 2) and consequently negatively affects team performance (Hypotheses 3 and 4). Thus, Study 1 tests the basic model presented in Figure 1. To test these hypotheses, in Study 1, we manipulated the level of power subjectively experienced by a formal team leader. Studies 2 and 3 sought to replicate and build upon these effects by replicating the tests of the basic model depicted in Figure 1 and then examining our two first-stage moderators of that model (formal authority and instrumentality awareness). In Study 2, we not only examined the effect of one's subjective sense of power on formal leadership dynamics but also investigated how the leader's formal role affected team members' reactions to the leader. Therefore, in Study 2, we used two manipulations, leader power and formal leadership role. We 
provided further support for Hypotheses 1-4, and we also tested our expectations about the role of formal authority in moderating our focal effects (Hypotheses 5 and 6). Finally, in Study 3 we again replicated our findings for Hypotheses 1-4 and tested the moderating role of the formal leader's awareness of the instrumentality of other team members (Hypotheses 7 and 8).

\section{STUDY 1}

\section{Participants and Design}

One hundred six undergraduates and MBA students at a university in the Southeastern United States participated in the study as part of a class exercise. The study employed one between-subjects factor: high-power formal leader vs. neutral-power formal leader. Students were randomly assigned to a team of five members (six teams had an additional sixth member in the role of observer) for a total of twenty teams. Students completed the study within their team, and the manipulation occurred only to the formal leader within each team.

\section{Procedures}

The day prior to the simulation, students were given instructions for the Everest Simulation developed by Harvard Business School. The web-based simulation uses the context of a Mount Everest expedition to reinforce student learning in team dynamics and leadership. Each team member received general information about the simulation and detailed information regarding their specific role. Students were randomly assigned to one of five roles on a team attempting to summit the mountain: leader, photographer, physician, environmentalist, or marathoner. The simulation occurred in six rounds lasting about 80 minutes total. During the simulation, students sat in break-out rooms with their teams and analyzed information on their own laptops while communicating with team members aloud and through the use of chat programs. In each round, team members analyzed information on weather, health conditions, 
supplies, goals, or hiking speed, and they determined how much of that information to communicate to their teammates. Team members then collectively discussed whether to attempt to reach the next camp en route to the summit. Throughout the simulation, the team had to decide how to effectively distribute supplies and oxygen bottles needed for the ascent. These decisions affected hiking speed, health, and ultimately the team's success in summiting the mountain. Failure to accurately communicate and analyze information as a team had negative consequences on team performance.

Our manipulation was administered only to students assigned to the formal leader role. In addition to the materials received by other team members, leaders in the teams assigned to the high-power formal leader condition received the power manipulation before receiving the rest of their information packet (formal leaders in the neutral-power condition did not receive the power manipulation). The high-power manipulation was adapted from previous research (Galinsky, Gruenfeld, \& Magee, 2003; Gruenfeld et al., 2008) and, consistent with our theorizing, was designed to elicit a high level of subjective feelings of power (rather than to manipulate objective or structural power). The instructions in the high-power manipulation read as follows:

Please think about a time when you had power over someone. By power, we mean a situation in which you controlled the ability of another person or persons to get something they wanted, or were in a position to evaluate those individuals. Please write 4-5 sentences describing this situation in which you had power.

In addition, the formal leaders in this condition were asked to write about how the experience they wrote about could help inform the strategies they would use in the team interactions the next day. The timing of the manipulation is important: Since the formal leaders in the high-power condition completed the power writing task before reading the information regarding the details of the simulation, they would be expected to encode the information about the simulation congruent with their high-power psychological state, such that participating in the 
simulation the next day would in fact reactivate the leaders' psychological feelings of power. Consistent with this notion, research by Babcock and Loewenstein (1997) has demonstrated that people selectively encode and evaluate information depending on their role. Accordingly, we expected that inducing the power experience immediately preceding the processing of the role information would lead participants to encode their roles in ways that are consistent with the power manipulation and that the effect of the power manipulation would consequently carry over into their experience the next day when they acted out the role.

The simulation recorded the level of goals the team was able to achieve, an objective measure of team effectiveness and performance. Students were also asked to complete an online survey individually after the survey was over, any time before the end of the day. The surveys administered to non-leaders included measures assessing their perceptions of the leader's amount of talking and openness. The surveys administered to the formal leaders included a measure assessing their perceived learning and manipulation checks.

\section{Measures}

Amount of talking. Participants indicated the percentage of the total time each member talked during the simulation. We investigated the appropriateness of aggregating this measure to the team level (defined as all team members without the formal leader). Interrater reliability among team members was high (ICC1 $=.63$, ICC2 $=.89, p<.001$; mean $r_{w g}=.96$ ), justifying aggregation at the team level (LeBrenton \& Senter, 2008). Thus, we created an aggregated score for the amount of talking of each team member.

Authority openness. We assessed the perceived openness of the formal leaders by following Grant et al.'s (2011) approach. In particular, we adapted items from existing measures of leader openness (Ashford et al., 1998; Detert \& Burris, 2007). Team members evaluated their 
formal leader on five items, using a 7-point Likert-type scale (1=disagree strongly, 7=agree strongly): "Open to new ideas," "Receptive to suggestions," "Interested in our ideas," "Rejected new ideas" (reverse-scored), and "Dismissed suggestions" (reverse-scored) $(\alpha=.88$ on average across the ratings of each team member role). Since the team members' ratings demonstrated good interrater reliability $\left(\mathrm{ICC} 1=.53, \mathrm{ICC} 2=.85, p<.01\right.$; mean $r_{w g}=.85$ ), we averaged them to compute an overall team-level score for perceived authority openness.

Team performance. The simulation program recorded the level of goals achieved by the team during the exercise (in percentage). Higher percentages indicate higher levels of goal achievement and thus higher levels of team performance.

Manipulation check. To test for the effect of the power manipulation, we asked the formal leaders to indicate the amount of power and influence they personally felt during the simulation using a 7-point scale (from $1=$ very little to $7=$ a great deal). The two items were highly correlated $(r=.71, p<.001)$, and we thus averaged them into a single measure $(\alpha=.82)$.

\section{Results}

Given that six teams had an observer, we controlled for team size in all our analyses. Team size was not a significant predictor of any of these results, so we do not discuss this variable further.

Manipulation check. We first checked whether our manipulation was successful by examining the ratings the formal leaders provided on the question regarding the amount of power and influence they felt throughout the simulation. Formal leaders in the high-power condition felt more powerful $(M=5.50, S D=0.75)$ than did those in the neutral-power condition $(M=4.20$, $S D=0.54), F(1,17)=18.91, p<.001$. 
Amount of talking. Team members reported that their formal leaders talked for a higher percentage of the allotted time for the simulation in the high-power condition $(M=32.73 \%$, $S D=6.63)$ than in the neutral-power condition $(M=18.70 \%, S D=2.68), F(1,17)=39.93, p<.001$. Consistent with this finding, team members reported that non-leaders talked for a lower percentage of the allotted time in the high-power condition than in the neutral-power condition. Thus, Hypothesis 1 was supported.

Authority openness. Members reported lower perceptions of openness in the high-power condition $(M=4.84, S D=0.56)$ than in the neutral-power condition $(M=5.37, S D=0.43)$, $F(1,17)=5.78, p<.05$. Thus, Hypothesis 2 was supported.

Team performance. Teams achieved a higher level of their team goals in the neutralpower condition $(M=76.20 \%, S D=11.92)$ than in the high-power condition $(M=59.00 \%$, $S D=13.12), F(1,17)=8.99, p<.01$. Thus, Hypothesis 3 was supported.

Mediation analyses. Hypothesis 4 predicted that the negative effect of the formal leader's subjective feelings of power on team performance would be mediated by talking and perceptions of authority openness (in that order). We therefore examined the three-stage mediated path model as depicted in Figure 1. To do so, we conducted three regressions, each controlling for team size. We first regressed the formal leader's amount of talking on power $(\mathrm{B}=14.03[\mathrm{SE}=2.22], \beta=.83, t=6.32, p<.001)$; we then regressed authority openness on the formal leader's amount of talking $(\mathrm{B}=-0.048[\mathrm{SE}=0.01], \beta=-.76, t=-5.02, p<.001)$; we then regressed team performance on authority openness $(\beta=.56, p=.012)$ and formal leader power $(\beta=-.31$, $p=.12$ ). We used a bootstrap analysis to construct bias-corrected confidence intervals based on 1,000 random samples with replacement from the full sample (MacKinnon, Fairchild, \& Fritz, 2007; Shrout \& Bolger, 2002). The bootstrap analysis showed that the $95 \%$ bias-corrected 
confidence interval for the size of the indirect effect did not include zero (-22.49 to -0.156$)$, suggesting a significant indirect effect and supporting our path model depicted in Figure 1. Thus, Hypothesis 4 was supported.

\section{Discussion}

The results of Study 1 supported our argument that a formal leader's experience of power leads to increased leader talking, which decreases the perceived openness of the leader and consequently diminishes team performance (as well as leader learning). By doing most of the talking, powerful formal leaders conveyed a sense that they were not open to others' input, and this dynamic produced a lower level of team performance as measured by the team's ability to reach their goals in the simulation.

\section{STUDY 2}

Study 2 was designed to further investigate the role of leader power on team performance by distinguishing between the effects of the formal leadership position and the leader's psychological experience of power. As explained in Hypotheses 5 and 6, we expect that the negative effect of leader power on team communication and performance emerges only when the leader holds a formal position of authority. We test this expectation in the context of a hiddenprofile task. Hidden-profile tasks are team tasks that contain a correct or best alternative and in which the information about these alternatives is distributed among the team members such that no team member can detect which alternative is the best by relying exclusively on his or her own information alone (see Stasser, 1992; Winquist \& Larson, 1998). Hidden-profile tasks can be solved only if the team members exchange and integrate their unshared information and thereby detect the decisional implication of the full information set.

\section{Participants and Design}


One-hundred forty-four individuals (68 male; $M_{a g e}=22.24, S D=2.60 ; 125$ students) from a city in the Northeastern United States participated in the study for $\$ 20$ plus an additional bonus based on team performance. The study employed two between-subjects factors: power (highpower vs. neutral-power) and formal leadership role (formal leader vs. no formal leader). Participants were randomly assigned to a team of three members (for a total of 48 teams).

\section{Procedure}

Participants worked in teams of three to solve a murder mystery (adapted from Stasser \& Stewart, 1992). They were given 20 minutes to read their materials about a homicide investigation individually. The materials included a (fictional) newspaper article about a murder, a set of interviews with suspects, and other supplementary materials, such as maps and a note from the victim to one of the suspects. The materials provided 45 shared clues and eight unique clues. When all of the clues are considered together, the materials make it clear which suspect is the guilty party. However, because the critical clues were distributed across the three team members, the correct solution to the murder mystery was unlikely to be discovered unless team members shared and discussed their uniquely held information.

The packets of materials also contained our manipulations of power and authority. We again used the writing task as the power manipulation, this time administered on the same day as the team discussion. The high-power manipulation was consistent with that used in the first study. In the neutral-power condition, the instructions read as follows:

Please recall the last time you were at the supermarket shopping for groceries. Please write 4-5 sentences describing this situation and one item or product that you purchased during the visit.

In the high-power condition, one randomly chosen participant in each team completed the highpower writing task. In the neutral-power condition, one randomly chosen participant in each 
team completed the neutral-power writing task. Thus, each team consisted of two team members who received no writing task and one team member who received either the high-power or neutral-power writing task.

We used nametags to manipulate formal leader status: all participants used nametags, but individuals in the formal leader role received nametags labeled "LEADER." The formal leader role manipulation always occurred for the individual who received a writing task, such that this individual either was labeled "LEADER" or was not. In addition, because there were eight unique clues, the individual who engaged in the writing task was always assigned to the role that had two unique clues, while the other participants were always assigned to one of the two roles that had three unique clues.

After reviewing their materials and engaging in any writing tasks to which they were assigned, participants were then asked to discuss the case with their team. Teams used break-out rooms for their team discussion; they had 30 minutes to reach a consensus on who committed the murder. After the team discussion, each team indicated one suspect that they believed was the guilty party. Next, participants completed post-discussion questionnaires with measures of the study variables.

\section{Measures}

Amount of talking. As in Study 1, each participant indicated the percentage of the total time each member talked during the team discussion. In our analyses, we used the participants' estimates of the percentage of talking time taken up by the person who engaged in the writing task. Interrater reliability among team members on this measure was high $(\mathrm{ICC} 1=.45, \mathrm{ICC} 2=.62$, $p<.01$; mean $\left.r_{w g}=.95\right)$, so we aggregated this measure at the team level. 
Team open communication. Each member indicated the extent to which he or she agreed with each of four statements ( $1=$ strongly disagree, $7=$ strongly agree) measuring communication openness: 1) All members had a chance to express opinions; 2) Team members listened to each others' input; 3) Members held back in fear of what others thought (reversescored); and 4) Members were free to make positive and negative comments. This scale was adapted from Barry and Stewart (1997). We averaged the four items into a single score ( $\alpha>$.70 for each team member role). Because the team members achieved good interrater reliability $\left(\mathrm{ICC} 1=.21\right.$, ICC2 $=.44, p<.02 ;$ mean $\left.r_{w g}=.86\right)$, we averaged their rating to create a team-level score.

Team performance: Decision. Participants indicated their team decision by checking "the name of the one suspect your group believes murdered Robert Guion" (all responses agreed). Team decision performance was based on whether the team chose the correct suspect. This was a dichotomous dependent variable ( $1=$ correct, $0=$ not correct).

Team performance: Learning. The materials for the team task included eight clues that were unique and not shared among team members. In the final questionnaire, we listed these clues together with some other filler clues and asked members to indicate whether during the team discussion they discovered information consistent with the listed clues. For each member, we then counted the number of unshared cues (out of eight) they reported learning about during the team discussion. Because the team members achieved good interrater reliability on this measure $\left(\mathrm{ICC} 1=.50, \mathrm{ICC} 2=.67, p<.001 ;\right.$ mean $r_{w g}=.77$ ), we averaged their ratings to form a measure of team learning performance

Autocratic leadership style. While we did not include autoctratic leadership style in our formal hypotheses, we measured it in this study as an additional check on our theoretical logic. 
Specifically, we have argued that the interactive effect of the subjective experience of power and formal authority on talking, communication, and performance is not simply an additive effect. That is, we do not expect that both variables increase talking and that the effects simply magnify one another when combined. Instead, we expect that the leader's subjective experience of power increases attempts at dominating interpersonal interactions in general (both verbal and nonverbal), and that it is other team members' reactions (which are dependent upon the leader's level of formal authority) that determine whether these attempts at dominance actually spill over to affect the communication and performance of the team. This line of reasoning suggests that subjective power increases dominance but formal authority does not; instead, formal authority simply determines how others react to attempts at dominance. If this line of reasoning is correct, formal authority should not moderate the effect of subjective power on attempts at dominating but should only moderate the effect of subjective power on team dynamics that require team interaction to emerge, such as talking, communications, and performance. Because autocratic style represents the individual's unilateral adoption of a dominating style rather than emergent behavior that involves the consent of all team members, we would not expect to see an interaction between subjective power and formal authority on autocratic style but rather a main effect of subjective power.

In order to test this expectation, we used the measure developed by Chen, Eberly, Chiang, Fahr, and Cheng (in press) to assess autocratic leadership behaviors. Team members were asked to evaluate the individuals who engaged in the writing task (whether they were labeled a "leader" or not) on this measure. This measure includes items that assess perceptions of an individual's leadership behavior and intentions that are not contingent on other team members' cooperation and consent (e.g., "This team member behaved in a commanding fashion" and "This team 
member seemed to want to exercise discipline over others"). We averaged the items from the scale into a single score $(\alpha=.69$ for member 1 and $\alpha=.75$ for member 2$)$. Because the team members achieved good interrater reliability (ICC1=.56, ICC2=.73, $p<.001$; mean $r_{w g}=.96$ ), we averaged their ratings.

Manipulation checks. The manipulation check for power was conducted on participants who received one of the writing tasks (both formal leaders and individuals who were not assigned the formal leader position). To check the manipulation of power, these individuals were asked to respond to two items: "How much influence do you feel that you had over the team decision task?" and "How much power did you personally feel during the team decision task?" These items were averaged to form a score of experienced power $(\alpha=.80)$. We also asked individuals to complete the sense of power scale we used in the pilot study (Anderson \& Galinsky, 2006). We averaged the eight items included in the scale to form a score of sense of power $(\alpha=.82)$. To check the formal leader manipulation, the final questionnaire asked participants to indicate whether there was a formal leader in their team.

\section{Results}

Manipulation checks. We started by examining whether our power manipulation was effective by using 2 (power) X 2 (formal leadership) between-subjects ANOVAs. Individuals who engaged in the writing task rated themselves as more powerful in the high-power condition $(M=5.74, S D=0.69)$ than in the neutral-power condition $(M=5.00, S D=0.84), F(1,44)=10.69$, $p=.002$. These individuals' ratings of their sense of power were consistent with the first manipulation check; participants in the high-power condition reported feeling more powerful $(M=5.69, S D=0.58)$ than did individuals in the neutral-power condition $(M=5.17, S D=0.73)$, $F(1,44)=7.06, p=.011$. Neither our formal leadership manipulation nor the interaction between 
the two manipulations significantly affected these ratings. As for the formal leadership manipulation, we confirmed that team members in the formal-leader condition reported having a formal leader, whereas team members in the no-formal-leader condition reported not having a formal leader.

Amount of talking. A 2 (power) X 2 (formal leadership) between-subjects ANOVA with team members' answers for the amount of time the individual who engaged in the writing task talked during the team discussion revealed a main effect of power, $F(1,44)=9.46, p=.004)$ and a marginally significant interaction effect, $F(1,44)=3.71, p=.061$. When the team had a formal leader, power positively influenced the leader's amount of talking as perceived by their team members $\left(M_{\text {high_power }}=42.39 \%, S D=8.16\right.$ vs. $\left.M_{\text {neutral_power }}=33.26 \%, S D=2.91\right), F(1,44)=12.54$, $p=.001$. This finding provides additional support for Hypothesis 1 . When the team did not have a formal leader, team members reported that the individual who engaged in the writing task talked about the same amount of time independent of the power manipulation $\left(M_{\text {high_power }}=36.02 \%\right.$, $S D=6.73$ vs. $\left.M_{\text {neutral_power }}=33.92 \%, S D=6.22\right), F(1,44)<1, p=.48$. This finding lends support to Hypothesis 5.

Team open communication. In a similar 2 (power) X 2 (formal leadership) betweensubjects ANOVA, we found only a significant interaction effect, $F(1,44)=3.92, p=.05$. When the team had a formal leader, there was a negative effect of power on team open communication $\left(M_{\text {high_power }}=5.68, S D=1.16\right.$ vs. $\left.M_{\text {neutral_power }}=6.30, S D=0.50\right), F(1,44)=4.73, p=.035$, again supporting Hypothesis 2. When the team did not have a formal leader, members reported about the same level of open communication independent of the power manipulation $\left(M_{\text {high_power }}=6.44\right.$, $S D=0.43$ vs. $\left.M_{\text {neutral_power }}=6.26, S D=0.46\right), F(1,44)<1, p=.53$. This finding lends further support to Hypothesis 5 . 
Team performance. Next, we examined team performance. To do so, we used binary logistic regression, using contrast-coded dummy variables for power (high-power $=1$, neutralpower $=-1$ ) and authority (formal leader $=1$, control $=-1$ ). Only the interaction was significant $(\mathrm{B}=-.62[\mathrm{SE}=.31], \mathrm{Wald}=3.91, d f=1, p=.048)$ (see Figure 2). When the team had a formal leader, a higher percentage of teams reached the right solution in the neutral-power condition than in the high-power condition $(75.0 \%$ vs. $25.0 \%), \chi^{2}(1, N=24)=6.00, p=.014$. This finding supports Hypothesis 3 . When the team did not have a formal leader, about the same percentage of teams reached the right solution, independent of the power manipulation (54.5\% vs. $61.5 \%)$, $\chi^{2}(1, N=24)<1, p=.73$. This finding lends further support to Hypothesis 5 .

Insert Figure 2 about here

Team learning performance. We next examined team learning performance, which was measured by averaging across the team the number of unique facts learned by the team members (out of eight unique facts that were included in the task). In a 2 (power) X 2 (formal leadership) between-subjects ANOVA, we found a marginally significant interaction effect $(F[1,44]=3.86$, $p=.056$ ). When the team had a formal leader, there was a negative effect of power on team learning performance ( $M_{\text {high_power }}=4.17, S D=0.78$ vs. $\left.M_{\text {neutral_power }}=5.38, S D=1.61\right), F(1,44)=5.54$, $p=.023$, again supporting Hypothesis 3 . When the team did not have a formal leader, the power manipulation did not affect members' level of learning $\left(M_{\text {high_power }}=5.34, S D=1.39\right.$ vs. $\left.M_{\text {neutral_power }}=5.32, S D=1.06\right), F(1,44)<1, p=.60$. This finding lends further support to Hypothesis 5.

\section{Moderated Mediation}


We next examined Hypothesis 6, which predicted that the three-stage mediated path model depicted in Figure 1 would be moderated by formal authority in the first stage (i.e., in the path between power and talking). We began by focusing on team decision performance as the dependent variable. To explore this hypothesis, we followed the advice of Edwards and Lambert (2007), who recommend running a series of regressions on the mediators and the dependent variable and using the results of these regressions to generate a reduced form equation (i.e., that includes only exogenous variables as predictors), which is used to compute simple paths that constitute the indirect effect of the independent variable at different levels of the moderator variable. Therefore, we first regressed formal leaders' amount of talking on power (high-power = 1 , neutral power $=0)$, authority $(1=$ formal leader, $0=$ control $)$, and the interaction between the two $(\mathrm{B}=7.03$ [SE=3.65], $\beta=.43, t=1.93, p=.06)$; we then regressed openness on amount of talking $(\mathrm{B}=-0.05[\mathrm{SE}=0.01], \beta=-.51, t=-3.97, p<.001)$; and, finally, we used binary logistic regression to estimate the effect of openness $(\mathrm{B}=1.23[\mathrm{SE}=.58]$, Wald=4.56, $d f=1, p=.033)$ and power $(\mathrm{B}=-.79$ [SE=.63], Wald=1.57, $d f=1, p=.21$ ) on team decision performance. The bootstrap analysis (MacKinnon et al., 2007; Shrout \& Bolger, 2002) indicated that the indirect effect of power on team decision performance as mediated through leader talking and open communications was significant when the leader held a formal position of authority (95\% bias-corrected confidence interval: $-2.32,-0.03)$. This finding again supports Hypothesis 4 and our path model depicted in Figure 1. Further, as expected, the bootstrap analysis revealed that the indirect path was not significant when the leader did not hold a formal position of authority (95\% bias-corrected confidence interval: $-0.90,0.14)$. This finding supports Hypothesis 6.

We next conducted the same mediation analysis using team learning performance as the dependent variable. In the series of regression equations, we substituted the third equation for 
one in which team learning was regressed on open communications $(\mathrm{B}=0.50[\mathrm{SE}=0.26], \beta=.28$, $t=1.97, p=.055)$ and power $(\mathrm{B}=-0.36[\mathrm{SE}=0.38], \beta=-.14, t=-0.97, p=.34)$. The bootstrap analysis indicated that the indirect effect of power on team learning performance as mediated through leader talking and open communications was significant when the leader held a formal position of authority (95\% bias-corrected confidence interval: -0.82, -0.01). This finding again supports Hypothesis 4 and our path model depicted in Figure 1. Further, as expected, the bootstrap analysis revealed that the indirect path was not significant when the leader did not hold a formal position of authority (95\% bias-corrected confidence interval: $-0.30,0.04)$. This finding supports Hypothesis 6.

\section{Supplementary analysis on Autocratic Leadership Style}

We conducted a supplementary analysis as a final check on our expectation that taking on an autocratic demeanor or style, unlike talking, is not dependent upon the consent of other team members so would not be affected by the manipulation of formal authority. To do so, we conducted a 2 (power) X 2 (formal leadership) between-subjects ANOVA using team members' aggregate rating of the autocratic style of the individual who engaged in the writing task as the dependent variable. Consistent with our expectations, this analysis revealed only a main effect of power, $F(1,44)=4.94, p=.032$ : in the high-power conditions, members perceived the individual to have used a more autocratic style than did those in the neutral-power conditions $\left(M_{\text {high_power }}=1.66, S D=0.66\right.$ vs. $\left.M_{\text {neutral_power }}=1.35, S D=0.32\right)$. As expected, this main effect of power was not moderated by formal authority. Consistent with our arguments, individuals who received the power prime were perceived as acting autocratically whether they were formal leaders or not; however, they only succeeded in talking more (and thereby limiting open communication and decreasing team performance) if they had the formal leader title. This 
supports our contention that the reactions of other team members (based on the leaders' levels of formal authority) to the leaders' dominating behavior were the crucial determinants of whether the negative effects of the leaders' experience of power actually spilled over to affect the team's communications and performance.

Another important implication of this finding that we wish to highlight is that the effect of subjective power on autocratic tendencies is, while significant, fairly subtle. Leaders who wrote about power were rated at a mean level of 1.66 on the seven-point autocratic leadership style scale; thus, even the high power leaders scored below the mid-point of the scale. We wish to highlight this point because we believe that it substantiates our contention that two relatively subtle psychological tendencies (the tendency of subjective power to induce a more dominating interpersonal style on the one hand, and the tendency of formal authority to elicit deference from others, on the other hand) can combine in a way that has not-so-subtle effects on team talking, communication, and performance.

\section{Discussion}

The results of Study 2 replicated the findings from Study 1, indicating that a formal leader's experience of power produces greater proportions of team talking from the leader, lower levels of open communication in the team, and consequently diminishes team performance. Critically, these effects did not emerge when the person receiving the power manipulation was not a formal leader. These results suggest that other team members only cooperate and acquiesce to a leader's dominating behaviors when that leader is granted a formal position of authority, such as official team leader. Consistent with this line of reasoning, the findings for the autocratic leadership measure indicate that the power manipulation increased the dominating behavior of the individuals who engaged in the writing task regardless of their formal leadership status. Thus, 
it appears that the experience of power affects leadership behavior, but this behavior only affects the broader performance of the team when the leader exhibiting the behavior holds a formal position of authority.

\section{STUDY 3}

We designed a final study to test for an important boundary condition of the effects of leaders' power on team open communication and performance: leaders' awareness of their team members' instrumentality. We expected that a formal leader's awareness of the potential contributions of others would eliminate the negative effect of the leader's subjective experience of power on team open communication and team performance.

\section{Participants and Design}

One-hundred fifty-two individuals (68 male; $M_{a g e}=21.84, S D=2.65 ; 130$ students) from a city in the Northeastern United States participated in the study for $\$ 20$ plus an additional bonus based on team performance. (After each session, we selected one team among those that found the correct solution to the team task and gave each member a $\$ 20$ bonus payment.)

The study employed two between-subjects factors: power (high-power formal leader vs. neutral-power formal leader) and awareness of the instrumentality of team members (formal leader is reminded of instrumentality vs. not). Participants were randomly assigned to teams of four members (for a total of 38 teams).

\section{Procedure}

As case material, we used a modified version of the PB Technologies exercise developed by the Dispute Resolution Research Center at the Kellogg School of Management. In this exercise, the top management team of PB Technologies is asked to recommend to the CEO one of three finalists for the position of chief financial officer (CFO). For one candidate, the only 
common information is negative. However, if team members share information effectively, they discover that this candidate has the most positive profile overall. The other two candidates each have significant unshared negative information: one has a moderate amount of negative information, and the other has mostly negative information. The initial instructions described the objective of the study to be an investigation of effective decision making. The participants were informed that one candidate was clearly better than the other two. Participants were given 20 minutes to carefully read the materials individually.

In the high-power formal leader condition, one individual was provided with a formal nametag indicating that he/she was the team leader and was asked to write for a few minutes before the team discussion about a past experience of power and then about the influence that he/she would have over the team throughout the study (as in studies 1 and 2). In the neutralpower leader condition, we used the same public assignment of the leadership role through the formal nametag mechanism, and the leader received an extra page of instructions indicating that he/she was the team leader (as in the high-power leader condition) but did not engage in the writing task.

To manipulate the formal leader's awareness of the instrumentality of team members, we provided additional information to the participants in the role of formal leader. Specifically, in the instrumental-team-members condition, the instructions informed the formal leader that each member represented a different role. The instructions stated: "Each member in the team is representing a different role. So, everyone has something unique to contribute in this task. Given every team member's unique perspective, obtaining everyone's views of the situation can be critical in reaching a good decision." In the non-instrumental-team-members condition, the team leader did not receive these instructions. 
Both manipulations were contained in the case material. Immediately after reading the case material, participants sat at a table with their teams so that they could discuss the case together. They were given a piece of paper to record the team decision. After the allotted 20 minutes were over, each member completed a final questionnaire individually, which included the measures described below.

\section{Measures}

Amount of talking. As in Studies 1 and 2, each participant indicated the percentage of the total time each member talked during the team discussion. As before, we focused on the team members' perceptions of the amount of talking by the formal leader. Interrater reliability among team members was high (ICC1 $=.58, \mathrm{ICC} 2=.80, p<.001$; mean $\left.r_{w g}=.96\right)$, so we aggregated this measure at the team level.

Team open communication. We used the same measure of team open communication that we used in Study 2. We again averaged the four items into a single score $(\alpha>$.70 for each team member role). Because the team members achieved good interrater reliability (ICC1=.21, ICC2 $=.44, p<.02$; mean $\left.r_{w g}=.86\right)$, we averaged their rating.

Team decision performance. We assessed team performance using a dichotomous variable that was equal to one if the team reached the right solution by recommending the best candidate and zero otherwise.

Manipulation check: Power. To test for the effect of the power manipulation, we asked formal leaders to indicate the amount of power and influence they personally felt during the team decision task using a seven-point scale (from $1=$ very little to $7=a$ great deal). The two items were highly correlated $(r=.78, p<.001)$, and we thus averaged them into a single measure $(\alpha=.87)$. In 
addition, formal leaders answered the same eight-item sense of power scale we employed in the pilot study $(\alpha=.77)$. Thus, we tested the effect of the manipulation using both scales.

Manipulation check: Instrumentality. To test for the effect of the awareness of instrumentality manipulation, we asked formal leaders to indicate their agreement with four statements for each team member (using a seven-point scale, ranging from $1=$ strongly disagree, to $7=$ strongly agree): 1) This person provided useful input to help the team perform well; 2) Listening to the input from this person would have helped the team perform well on this task; 3) This person greatly contributed to team performance; and 4) This person greatly helped the team achieve its goals. We created an aggregate score of team members' instrumentality as judged by formal leaders by averaging formal leaders' answers across the four items $(\alpha>.81$ for the ratings about each of three team members being evaluated) and then by averaging these aggregate scores across the three team members $(\alpha=.91)$.

\section{Results}

Manipulation checks. We started by examining whether our manipulations were effective using 2 (power) x 2 (instrumentality awareness) between-subjects ANOVAs. Consistent with our manipulation, formal leaders rated themselves as more powerful in the highpower condition $(M=5.79, S D=1.06)$ than in the neutral-power condition $(M=4.79, S D=1.43)$, $F(1,34)=5.59, p=.024$. In addition, formal leaders' ratings of their sense of power were also consistent with our manipulation; formal leaders in the high-power condition reported feeling a higher sense of power $(M=5.51, S D=0.59)$ than did those in the neutral-power condition $(M=4.93, S D=0.95), F(1,34)=4.81, p=.035$. Neither our instrumentality manipulation nor the interaction between the two manipulations significantly affected these ratings. 
We then used formal leaders' ratings of team members' instrumentality to test the validity of our manipulation of instrumentality awareness. As expected, leaders in the instrumental condition rated team members as more instrumental $(M=6.50, S D=0.72)$ than did leaders in the non-instrumental condition $(M=5.62, S D=1.16), F(1,34)=7.72, p=.009$. Neither our power manipulation nor the interaction between the two manipulations had significant effects. Taken together, these results indicate that our manipulations were effective.

Amount of talking. A 2 (power) X 2 (instrumentality awareness) between-subjects ANOVA using team members' answers for the amount of time the formal leader talked during the team discussion revealed a main effect of power $(F[1,34]=10.33, p=.003)$ and a significant interaction effect $(F[1,34]=5.11, p=.03)$. When team members were not described as instrumental, the power manipulation had a positive effect on formal leaders' amount of talking as perceived by the team members $\left(M_{H P_{-} \text {leader }}=35.37 \%, S D=8.53\right.$ vs. $M_{N P_{-} \text {leader }}=23.89 \%$, $S D=3.73), F(1,34)=14.23, p=.001$. However, Levene's Test for Equality of Variances indicated that the assumption of homogeneity of variance was violated in this test, so we further examined this prediction using an unequal variance t-test, which further corroborated our prediction $(t(10.95)=3.70, p=.004$, thus providing further support for Hypothesis 1 . When team members were described as instrumental, team members described their formal leader as talking the same amount independent of the power manipulation $\left(M_{H P \_l e a d e r}=27.83 \%, S D=4.45\right.$ vs. $\left.M_{N P \_l e a d e r}=25.83 \%, S D=7.79\right), F(1,34)<1, p=.49$. These finding lend initial support to Hypothesis 7.

Team open communication. A 2 (power) X 2 (instrumentality awareness) betweensubjects ANOVA using open communication as the dependent variable revealed only a significant interaction between our two manipulations, $F(1,34)=4.47, p=.042$. When members 
were not described as instrumental, there was a negative effect of the power manipulation on team open communication $\left(M_{H P_{-} l e a d e r}=5.78, S D=0.76\right.$ vs. $\left.M_{N P_{-} l e a d e r}=6.44, S D=0.54\right)$, $F(1,34)=6.43, p=.016$. Thus, Hypothesis 2 was supported. When team members were described as instrumental, team members reported communicating equally well independent of leader power $\left(M_{H P \_l e a d e r}=6.25, S D=0.45\right.$ vs. $\left.M_{N P \_l e a d e r}=6.15, S D=0.44\right), F(1,34)<1, p=.69$. Taken together, these findings lend additional support to Hypothesis 7.

Team performance. Next, we examined team performance using exact logistic regression. Exact logistic regression was necessary because one of the cells in our 2 X 2 design (power, no instrumentality awareness) produced no correct answers on the dependent variable. In exact logistic regression, a p-value is calculated by determining the proportion of permutations of the data that would generate a distribution of outcomes at least as extreme as the observed outcome. The p-value for each parameter estimate is calculated conditionally based on the estimated value for the other parameters. Because exact logistic regression is based on counting permutations, the usual test statistics, based on $z$ or $\chi^{2}$ distributions, are not calculated. Therefore, we report only the coefficient estimates and p-values for these tests.

This analysis revealed no main effects and a marginally significant interaction between power and instrumentality, $\mathrm{B}=-2.32, p=.08$ (see Figure 3). As predicted, when team members were not described as instrumental, a higher percentage of teams reached the right solution in the neutral-power condition than in the high-power condition $(55.6 \%$ vs. $0 \%), \chi^{2}(1, N=18)=6.92$, $p=.009$, a finding that supports Hypothesis 3 . When team members were described as instrumental, about the same percentage of teams reached the right solution, independent of leader power $(50.0 \%$ vs. $60.0 \%), \chi^{2}(1, N=20)<1, p=.65$. These findings lend further support to Hypothesis 7. 
Insert Figure 3 about here

Moderated mediation. Next, we examined whether the instrumentality manipulation moderated the indirect effect depicted in Figure 1. To do so, we again used the approach recommended by Edwards and Lambert (2007). We first regressed leaders' amount of talking on power $($ high-power $=1$, neutral power $=0)$, instrumentality $(1=$ awareness reminder, $0=$ no reminder), and the interaction between the two $(\mathrm{B}=-9.48[\mathrm{SE}=4.20], \beta=-.56, t=-2.26, p=.03)$; we then regressed openness on amount of talking $(\mathrm{B}=-0.28[\mathrm{SE}=0.12], \beta=-.36, t=-2.28, p=.029)$; and finally, we used binary logistic regression to estimate the effect of openness ( $\mathrm{B}=5.82$ [SE=2.02], Wald=8.30, $d f=1, p=.004)$ and power $(\mathrm{B}=-1.05$ [SE=1.02], Wald=1.05, $d f=1, p=.30)$ on team decision performance. The bootstrap analysis (MacKinnon et al., 2007; Shrout \& Bolger, 2002) indicated that the indirect effect of power on team decision performance as mediated through leader talking and open communications was significant when the leader did not receive an instrumentality reminder (95\% bias-corrected confidence interval: $-80.01,0.00$, indicating a significance level of $p=.05)$. This finding again supports Hypothesis 4 and our path model depicted in Figure 1. Further, as expected, the bootstrap analysis revealed that the indirect path was not significant when the leader did not hold a formal position of authority (95\% biascorrected confidence interval: -25.55, 0.74). This finding supports Hypothesis 8.

\section{Discussion}

Study 3 replicated key findings from Studies 1 and 2. Specifically, when no mention was made of the instrumentality of team members, teams with formal leaders with a high level of subjective feelings of power reported higher levels of leader talking, indicated lower levels of 
open communication, and demonstrated lower levels of team performance compared to teams in the neutral-power condition. In addition, Study 3 supported our contention that leaders' awareness of the instrumentality of team members can eliminate these effects. Specifically, when team members were described as instrumental, the effects of formal leaders' feelings of power on leader talking, team open communication, and team performance were essentially eliminated. The results of Study 3 also further supported our prediction that leader talking and team open communication mediates the effect of leader power on team performance.

\section{General Discussion}

The results of three studies provide consistent evidence in support of our arguments. Specifically, Study 1 demonstrated that the subjective experience of power increases formal leaders' tendencies to verbally dominate social interactions and diminishes perceptions of authority openness, which in turn diminishes team performance. Mediation analyses provided support for our three-step causal path in which subjective power increases leader talking, which in turn decreases perceptions of authority openness, which finally transmits the negative effect onto team performance. Study 2 replicated these findings and further demonstrated the important role of team members' reactions to leader's behavior. Specifically, Study 2 showed that while subjective feelings of power increased leaders' autocratic tendencies, the leader's formal role (or lack thereof) determined team members' willingness to acquiesce to this dominant behavior. Thus, we found that the effects of subjective power on leader talking, team open communication, and team performance (both decision performance and learning performance) only emerged when leaders held a formal leadership role. Study 3 again replicated the findings from Studies 1 and 2 with respect to formal leaders and also identified an important boundary condition of these effects. Specifically, in Study 3, teams with subjectively powerful formal leaders reported higher 
levels of leader talking, indicated lower levels of team open communication, and exhibited lower team performance than teams in the control condition, but this only occurred when the formal leaders were not reminded of the instrumentality of their team members. When leaders were reminded that all team members had the potential to contribute to the team's success, these effects did not emerge. These findings support our contention that formal leaders' awareness of the instrumentality of their team members motivates them to overcome their tendency to discount others' perspectives and input; when formal leaders experiencing a high subjective sense of power are aware of the instrumentality of their team members, they are more encouraging of others' input, and the negative effect of power on team open communication is eliminated.

\section{Theoretical and Practical Implications}

We wish to highlight three key theoretical contributions of this research. First, we contribute to research on the impact of social hierarchy on learning and performance in teams and organizations (e.g., Bunderson, 2003a, 2003b). Specifically, researchers have called for a better understanding of the micro-processes by which hierarchy impedes team performance (Van der Vegt et al., 2010). Our research indicates that the concentration of power in a formal leader can be a crucial factor that leads to negative team performance. In particular, we demonstrate that the leader's subjective experience of power increases the leader's attempts to dominate team interactions. Furthermore, if the leader holds a formal position of authority, other team members are more inclined to defer to these dominating attempts. Therefore, when a formal leader experiences a heightened level of power, the leader is likely to verbally dominate team interactions, thus reducing the openness of communication in the team and consequently diminishing team performance. Identifying the micro-processes that produce the negative effect 
of hierarchy on team performance is a first step toward mitigating some of the negative effects that hierarchy can produce and thus represents an important theoretical and practical advance.

Second, the present paper shows that the psychological effect of power is not limited to the internal and behavioral effects on the individual experiencing either high or low power. We demonstrate that when formal leaders experience feelings of power, that experience affects the entire group in which the formal leader is situated. A formal leader's subjective experience of power influences collective outcomes by changing the leader's behavior, and the leader's formal position increases the likelihood that other team members will defer to his or her dominating behavior. Our findings therefore represent an important advancement of prior research on the effects of the psychological experience of power by showing that the effects transmit beyond the individual level to the team level.

Third, we advance research on the important role of followers in determining leadership dynamics (e.g., DeRue, 2011; Dvir \& Shamir, 2003; Howell \& Shamir, 2005) by highlighting that followers' consent is a crucial determinant of the effect of leaders' dominating behaviors on the performance of the group. Specifically, our research demonstrates that leaders' powerprompted dominant behaviors are less likely to negatively affect the team's performance if the leader lacks the legitimacy derived from holding a formal position of authority. The ways in which followers' consent moderates the effectiveness of leadership behaviors is an important area for further research. Indeed, we have argued that formal authority evokes deference, which suggests that deference was an unmodeled proximal moderator transmitting the moderating effect of formal authority onto the effects of subjective power. Future research could more directly test this implication. 
This research also has important practical implications for the role of leaders in promoting team performance. Specifically, our work indicates that it may be necessary for organizations and groups to take action to minimize the negative effects of formal leaders' psychological experiences of power on team performance. This goal may be pursued in multiple ways. One option would be to minimize the psychological experience of power among leaders by maintaining a relatively flat organizational structure and egalitarian culture. Alternatively, organizations could train leaders to cultivate high levels of authority openness and to encourage open team communications. Similarly, organizations may institute practices and policies that serve to remind leaders of the important contributions their subordinates have the capacity to make, thereby reminding leaders that those around them are instrumental to the pursuit of collective goals. Finally, organizations could encourage all members to question the legitimacy of formal leaders who take a dominating approach to social interactions. This tactic could delegitimize leaders' dominating behavior, which in turn would decrease team members' willingness to defer to formal leaders who engage in such behavior.

\section{Limitations and Directions for Future Research}

These contributions must be qualified in light of several limitations of our research, each of which signals directions for future research on this topic. A first limitation is our methodological approach. We conducted the three studies we described in controlled settings (the laboratory or the classroom), which may limit the external validly of our findings. However, the negative effect of hierarchy on team performance has been established in previous studies, and our goal here was to identify and explain the micro-processes that underlie these negative effects of power. By taking advantage of random assignment and manipulations of power that have been validated in previous research, our studies provided consistent and robust evidence 
that formal leaders' psychological experience of power can affect their teams' processes and performance in important ways. Moreover, the correlation between the effect sizes obtained in the field and those obtained in the lab are generally high (Anderson, Lindsay, \& Bushman, 1999). Therefore, we expect that further field-based investigations into these micro-processes would strengthen the generalizability of the present results and possibly uncover important boundary conditions of both the findings and the theory presented in this paper.

A second limitation is the type of team tasks we used. In all three studies, we employed tasks that require collaborative problem solving that involves team members sharing and integrating information and perspectives. There may be other types of tasks for which our findings would be less likely to hold. For example, complex tasks that require a high level of process coordination may benefit from a more dominating or autocratic approach to team leadership as long as there is a true differentiation of expertise and the leader can accurately identify each member's expertise (Lewis, 2004). In addition, in contexts that involve a high level of uncertainty or insecurity, team members may be comforted by the presence of a commanding leader, which may have a positive effect on performance. Similarly, autocratic leadership may be particularly beneficial in crisis situations where it is neither feasible nor desirable to obtain input from all team members. Also, in these tasks, there was no particular person who had more general expertise than others; when the leader has a much higher level of expertise than other team members, verbal dominance by the leader may have less of a negative effect. That said, if the leader has such a high level of expertise that other members' input is unnecessary, there is relatively little reason to use a team. Teams are most useful when information from multiple individuals needs to be integrated, and we argue, and our findings corroborate, that it is precisely 
in these situations that the psychological experience of power is most likely to produce negative effects for team communication and performance.

A third limitation of our methodological approach is that we did not record the conversations that took place among the teams and thus we relied primarily on self-reported measures of talking rather than observational data. Previous laboratory studies in this line of research have demonstrated high correlations between the reported talking time and recorded talking time (Tost, Gino, \& Larrick, 2011). However, future research in this area could record the conversations and code their content to attempt to clarify how power and authority affect the content of information exchanged in team meetings.

The theoretical contributions of the present research open up a broad range of new directions for future work. Our findings suggest there may be an intriguing cyclical relationship between power and leadership. Presumably, leadership success at lower levels of organizations increases the likelihood of promotion, which increases formal authority and very likely a subjective feeling of power. The research presented here suggests that, at least in some contexts, the simultaneous combination of authority and feelings of power could diminish the effectiveness of the leader at facilitating high levels of team performance. As a result, the very act of promoting someone could cause the performance of that person's team to suffer. Future research should investigate this possibility.

Furthermore, future research could examine how the subjective experience of power affects leaders' abilities to modify the amount of participation they solicit from team members based on their assessments of those team members' expertise and abilities (Vroom \& Jago, 1998). On the one hand, the dominating impulses brought about by feelings of power may diminish leaders' abilities to accurately assess others' expertise and abilities. On the other hand, 
the positive effect of feelings of power on the flexible allocation of attention (Guinote, 2007;

Overbeck \& Park, 2006) suggests that, to the extent that powerholders accurately assess others' abilities, they may be more effective than less powerful leaders at successfully soliciting appropriate information and feedback.

Future work could also explore how the subjective experience of power affects the behavior of team members other than a formal leader. How would our results differ if two individuals were simultaneously experiencing high subjective feelings of power? How would team members' inclinations to defer to a formal leader differ if the team members themselves were experiencing high subjective feelings of power?

Another important area of future inquiry concerns the moderators of the effects we have demonstrated. For example, it may be that certain personality types have more Machiavellian tendencies and would exhibit stronger effects of the experience of power on interpersonal dominance, while others may be more inclined to channel their experience of power in prosocial ways (Chen, Lee-Chai, \& Bargh, 2001). Similarly, some team members may be more or less inclined to defer to authority based on their personality type, interest in the issue being discussed, and relationship to the leader.

Finally, our research highlights the importance of developing a better understanding of the organizational-level antecedents of leaders' psychological experiences of power (e.g., does a hierarchical culture increase the frequency of these experiences?) and determining ways in which these factors can be modified to diminish the negative impact of a formal leader's power on team communications and performance. We hope the present research has laid the groundwork for the pursuit of these and related avenues of inquiry. 


\section{REFERENCES}

Agrell, A., \& Gustafson, R. 1996. Innovation and creativity in work groups. M. A. West (Ed.). Handbook of work group psychology: 314-343. London: Wiley

Anderson, C. A., \& Berdahl, J. L. 2002. The experience of power: Examining the effects of power on approach and inhibition tendencies. Journal of Personality and Social Psychology, 83(6): 1362-1377.

Anderson, C., \& Brown, C. E. 2010. The functions and dysfunctions of hierarchy. Research in Organizational Behavior, 30: 50-89.

Anderson, C. A., \& Galinsky, A. 2006. Power, optimism, and risk-taking. European Journal of Social Psychology, Special issue on social power, 36: 511-536.

Anderson, C. A., Lindsay, J. L., \& Bushman, J. 1999. Research in the psychological laboratory: Truth or triviality? Current Directions in Psychological Science, 8: 3-9.

Anderson, N.R., \& West, M.A. 1998. Measuring climate for work group innovation: Development and validation of the team climate inventory. Journal of Organizational Behavior, 19: 235-258

Ashford, S. J., Rothbard, N. P., Piderit, S. K., \& Dutton, J. E. 1998. Out on a limb: The role of context and impression management in selling gender-equity issues. Administrative Science Quarterly, 43: 23-57.

Babcock, L., \& Loewenstein, G. 1997. Explaining bargaining impasse: the role of self-serving biases. Journal of Economic Perspectives, 11: 109-126.

Bales, R. F., Strodtbeck, F. L., Mills, T. M., \& Roseborough, M. E. 1951. Channels of communication in small groups. American Sociological Review, 16: 461-468. 
Baron, R. M., \& Kenny, D. A. 1986. The moderator-mediator variable distinction in social psychological research: Conceptual, strategic, and statistical considerations. Journal of Personality and Social Psychology, 51(6): 1173-1182.

Barry, B., \& Stewart, G. L. 1997. Composition, process, and performance in self-managed groups: The role of personality. Journal of Applied Psychology, 82: 62-78.

Bass, B. M. 2008. The Bass handbook of leadership: Theory, research, and managerial applications. New York: Free Press.

Berdahl, J. L., \& Martorana, P. V. 2006. Effects of power on emotion and expression during a controversial group discussion. European Journal of Social Psychology, 36(4): 497-509.

Bunderson, J. S. 2003a. Recognizing and utilizing expertise in work groups: A status characteristics perspective. Administrative Science Quarterly, 48: 557-591.

Bunderson, J. S. 2003b. Team member functional background and involvement in management teams: Direct effects and the moderating role of power centralization. Academy of Management Journal, 46(4): 458-474.

Catmull, E. 2008. How Pixar fosters collective creativity. Harvard Business Review, 86(9): 6472.

Chen, S., Lee-Chai, A.Y. \& Bargh, J.A. (2001). Relationship orientation as a moderator of the effects of power. Journal of Personality and Social Psychology, 80, 173-187

Chen, X. P., Eberly, M., Chiang, T. J., Farh, J. L., \& Cheng, B. S. (In press). Affective trust in Chinese leaders: Linking paternalistic leadership to employee performance. Journal of Management.

De Dreu, C.K., \& West, M.A. 2001. Minority dissent and team innovation: The importance of participation in decision-making. Journal of Applied Psychology, 86(6): 1191-201. 
DeChurch, L. A., Hiller, N. J., Toshio, M., Doty, D., \& Salas, E. 2010. Leadership across levels: Levels of leaders and their levels of impact. The Leadership Quarterly, 21: 1069-1085.

DeRue, D. S. (2011). Adaptive leadership theory: Leading and following as a complex adaptive process. Research in Organizational Behavior, 31: 125-150.

Detert, J. R., \& Burris, E. R. (2007). Leadership behavior and employee voice: Is the door really open? Academy of Management Journal, 50: 869-884.

Dionne, Sh. D., Yammarino, F.J., Atwater, L.E, \& Spangler, W.D. (2004). Transformational leadership and team performance. Journal of Organizational Management, 17(2): 177194.

Drach-Zachary, A., \& Somech, A. (2001). Understanding team innovation: The role of team processes and structures. Group Dynamics: Theory, Research and Practice, 5(2): 111123.

Dvir, T., \& Shamir, B. 2003. Follower developmental characteristics as predicting transformational leadership: A longitudinal field study. The Leadership Quarterly, 14: $327-344$.

Edmondson, A. C. 2003. Speaking up on the operating room: How team leaders promote learning in interdisciplinary action teams. Journal of Management Studies, 40(6): 14191452.

Edwards, J. R., \& Lambert, L. S. 2007. Methods for integrating moderation and mediation: A general analytical framework using moderated path analysis. Psychological Methods, 12: $1-22$.

Fiske, S. T. 1993. Controlling other people: The impact of power on stereotyping. American Psychologist, 48(6): 621-628. 
French, J. R. P., \& Raven, B. 1959. The bases of social power. In D. Cartwright \& A. Zander (Eds.), Group dynamics (pp. 150-167). New York: Harper and Rowe.

Galinsky, A. D., Gruenfeld, D. H, \& Magee, J. C. 2003. From power to action. Journal of Personality and Social Psychology, 85: 453-466.

Galinsky, A. D., Magee, J. C., Inesi, M. E., and Gruenfeld, D. H. 2006. Power and perspectives not taken. Psychological Science, 17: 1068-1074.

Gardner, H., Gino, F., \& Staats, B. (2012). Dynamically integrating knowledge in teams: A resource-based view of team performance. Academy of Management Journal, 55(4).

Georgesen, J. C., \& Harris, M. J. 1998. Why's my boss always holding me down? A metaanalysis of power effects on performance evaluations. Personality and Social Psychology Review, 2(3): 184-195.

Gollwitzer, P. M., Heckhausen, H., \& Steller, B. 1990. Deliberative vs. implemental mind-sets: Cognitive tuning toward congruous thoughts and information. Journal of Personality and Social Psychology, 59: 1119-1127.

Goodwin, S. A., Gubin, A., Fiske, S. T., \& Yzerbyt, V. Y. 2000. Power can bias impression processes: Stereotyping subordinates by default and by design. Group Processes and Intergroup Relations, 3(3): 227-256.

Goodwin, S. A., Operario, D., \& Fiske, S. T. 1998. Situational power and interpersonal dominance facilitate bias and inequality. Journal of Social Issues, 54(4): 677-698.

Grant, A., Gino, F., \& Hofmann, D. 2011. Reversing the extraverted leadership advantage: The role of collective employee proactivity. Academy of Management Journal. In press. 
Gruenfeld, D. H., Inesi, M. E., Magee, J. C., \& Galinsky, A. D. 2008. Power and the objectification of social targets. Journal of Personality and Social Psychology, 95: 111127.

Guinote, A. 2007. Power and goal pursuit. Personality and Social Psychology Bulletin, 33: 1076-1087.

Guzzo, R. A., \& Dickson, M. W. 1996. Teams in organizations: Recent research on performance and effectiveness. Annual Review of Psychology, 47: 307-338.

Halevy, N., Chou, E. Y., \& Galinsky, A. D. 2011. A functional model of hierarchy: Why, how, and when vertical differentiation enhances group performance. Organizational Psychology Review, 1: 32-52.

Hamilton, G. G., \& Biggart, N. W. 1985. Why people obey: Theoretical observations on power and obedience in complex organizations. Sociological Perspectives, 28: 3-28.

Hogg, M. A. 2001. A social identity theory of leadership. Personality and Social Psychology Review, 5:184-200.

Howell, J.M., \& Shamir, B. 2005. The role of followers in the charismatic leadership process: Relationships and their consequences. Academy of Management Review, 30: 96-112.

Keltner, D., Gruenfeld, D.H., and Anderson, C. 2003. Power, approach, and inhibition. Psychological Review, 110(2), 265-284.

Kipnis, D. 1972. Does power corrupt? Journal of Personality and Social Psychology, 24(1): $33-41$.

Klein, K. J., Ziegert, J. C., Knight, A. P., \& Xiao, Y. 2006. Dynamic delegation: Shared, hierarchical, and deindividualized leadership in extreme action teams. Administrative Science Quarterly, 51: 590-621. 
LeBrenton, J. M., \& Senter, J. L. 2008. Answers to 20 questions about interrater reliability and interrater agreement. Organizational Research Methods, 11: 815-852.

Lewis, K. 2004. Knowledge and performance in knowledge-worker teams: A longitudinal study of transactive memory systems. Management Science, 50: 1519-1533.

Locke, J. 1988. An essay concerning human understanding. Oxford, UK: Clarendon Press. (Original work published 1689).

Lord, R. G. 1977. Functional leadership behavior: Measurement and relation to social power and leadership perceptions. Administrative Science Quarterly, 22(1): 114-133.

MacKinnon, D. P., Fairchild, A. J., \& Fritz, M. S. 2007. Mediation analysis. Annual Review of Psychology, 58: 593-614.

Marks, M. A., Mathieu, J. E., \& Zaccaro, S. J. 2001. A temporally based framework and taxonomy of team process. The Academy of Management Review, 26(3): 356-376.

Martin, A., \& Bal, V. 2006. The state of teams: CCL research report. Greensboro, NC: Center for Creative Leadership .

Mathieu, J. E., Heffner, T. S, Goodwin. G. F, Salas, E., \& Cannon-Bowers, J. A. 2000. The influence of shared mental models on team process and performance. Journal of Applied Psychology, 85(2): 273-83.

Mayer, D. M., Kuenzi, M., Greenbaum, R., Bandes, M., \& Salvador, R. B. 2009. How low does ethical leadership flow? Test of a trickle-down model. Organizational Behavior and Human Decision Processes, 108: 1-13.

Mechanic, D. 1962. Sources of power of lower participants in complex organizations. Administrative Science Quarterly, 7(3): 349-364. 
Mehra, A., Smith, B. R., Dixon, A. L., \& Robertson, B. 2006. Distributed leadership perceptions and team performance. The Leadership Quarterly, 17: 232-245.

Orbell, J. M., van de Kragt. A. J. C., \& Dawes, R. M. 1988. Explaining discussion- induced cooperation. Journal of Personality and Social Psychology, 54: 811-819.

Overbeck, J. R. 2010. Concepts, domains, and historical perspectives on power. In A. Guinote \& T. K. Vescio (Eds.), The Social Psychology of Power. New York: Guilford Press

Overbeck, J. R., \& Park, B. 2006. Powerful perceivers, powerless objects: Flexibility of powerholders' social attention. Organizational Behavior and Human Decision Processes, 99(2): 227-243.

Peabody, R. .L. 1962. Perceptions of organizational authority: A comparative analysis. Administrative Science Quarterly, 6: 463-482.

Pearson, C. A. L. 1991. An assessment of extrinsic feedback on participation, role perceptions, motivation, and job satisfaction in a self-managed system for monitoring group achievement. Human Relations, 44: 517-37.

Proell, C., \& Sauer, S. J. 2011. "Stock" options: The debilitating effects of autonomy and choice on self-perceptions of power. Available at SSRN: http://ssrn.com/abstract $=1777522$

Ridgeway, C. L., \& Berger, J. 1986. Expectations, legitimation, and dominance behavior in task groups. American Sociological Review, 51: 603-617.

Rus, D., van Knippenberg, D., \& Wisse, B. 2010. Leader power and leader self-serving behavior: The role of effective leadership beliefs and performance information. Journal of Experimental Social Psychology, 46: 922-933. 
Schaubroeck, J., Lam, S. S. K., \& Cha, S. E. 2007. Embracing transformational leadership: Team values and the impact of leader behavior on team performance. Journal of Applied Psychology, 92(4): 1020-1030.

Schoel, C., Bluemke, M., Mueller, P., \& Stahlberg, D. 2011. When autocratic leaders become an options: Uncertainty and self-esteem predict implicit leadership preferences. Journal of Personality and Social Psychology, 101: 521-540.

See, K. E., Morrison, E. W., Rothman, N. B., \& Soll, J. B. 2011. The Detrimental Effects of Power on Confidence, Advice Taking, and Accuracy. Organizational Behavior and Human Decision Processes, 116: 272-285.

Shrout, P. E., \& Bolger, N. 2002. Mediation in experimental and non-experimental studies: New procedures and recommendations. Psychological Methods, 7: 422-445.

Smith, K. G., Smith, K. A., Olian. J. D., Sims, H. P., O’Bannon, D. P., \& Scully, J. A. 1994. Top management team demography and process: The role of social integration and communication. Administrative Science Quarterly, 39(3): 412-438.

Stasser, G. 1992. Pooling of unshared information during group discussion. In S. Worchel, W. Wood, \& A. Simpson (Eds.), Group process and productivity (pp. 48-67). Newbury Park, CA: Sage.

Stasser, G., \& Stewart, D. 1992. Discovery of hidden profiles by decision-making groups: Solving a problem versus making a judgment. Journal of Personality and Social Psychology, 63: 426-434.

Stein, R. T., \& Heller, T. 1979. An empirical analysis of the correlations between leadership status and participation rates reported in the literature. Journal of Personality and Social Psychology, 37: 1993-2002. 
Stogdill, R. M. 1950. Leadership, membership, and organizations. Psychological Bulletin, 47: 114.

Tangirala, S., Green, S. G., \& Ramanujam, R. 2007. In the shadow of the boss's boss: Effects of supervisors' upward exchange relationships on employees. Journal of Applied Psychology, 92(2): 309-320.

Thibaut, J. W., \& Kelley, H. H. 1959. The social psychology of groups. New York: Wiley.

Tost, L. P., Gino, F., Larrick, R. P. 2011. When power makes others speechless: The negative impact of leader power on team performance. Academy of Management Annual Conference.

Tyler, T. R. 1997. The psychology of legitimacy: A relational perspective on voluntary deference to authorities. Personality and Social Psychology Review, 1: 323-345.

Van der Vegt, G. S., de Jong, S. B., Bunderson, J. S., \& Molleman, E. 2010. Power asymmetry and learning in teams: The moderating role of performance feedback. Organization Science, 21: 347-361.

Vroom, V. H. \& Jago, A. G. 1998. On interdependence and levels of analysis. In F. Yammarino \& F. Dansereau (Eds.), Leadership: The multiple-level approaches. Greenwich, CT: JAI Press, 183-189.

West, M. A. 1990. The social psychology of innovation in groups. M.A. West \& J. L Farr (Eds.) Innovation and creativity in work: Psychological and Organizational Strategies: 309333. London: Wiley.

Winquist, J. R., \& Larson, J. R. 1998. Information pooling: When it impacts group decision making. Journal of Personality and Social Psychology, 74: 371-377. 
Leader Power and Team Performance 55 


\section{FIGURE 1}

The Causal Path for the Main Effect of Formal Leader Power on Team Performance

\begin{tabular}{|c|c|c|c|c|c|c|}
\hline \multirow{3}{*}{$\begin{array}{l}\text { Formal } \\
\text { Leader } \\
\text { Power }\end{array}$} & \multirow{3}{*}{+} & \multirow{3}{*}{$\begin{array}{l}\text { Formal } \\
\text { Leader's } \\
\text { Amount of } \\
\text { Talking }\end{array}$} & \multirow{3}{*}{-} & \multirow{3}{*}{$\begin{array}{c}\text { Authority } \\
\text { Openness and } \\
\text { Team Open } \\
\text { Communication }\end{array}$} & & \multirow{3}{*}{$\begin{array}{c}\text { Team } \\
\text { Performance }\end{array}$} \\
\hline & & & & & + & \\
\hline & & & & & & \\
\hline
\end{tabular}


FIGURE 2

Team Performance, Study 2

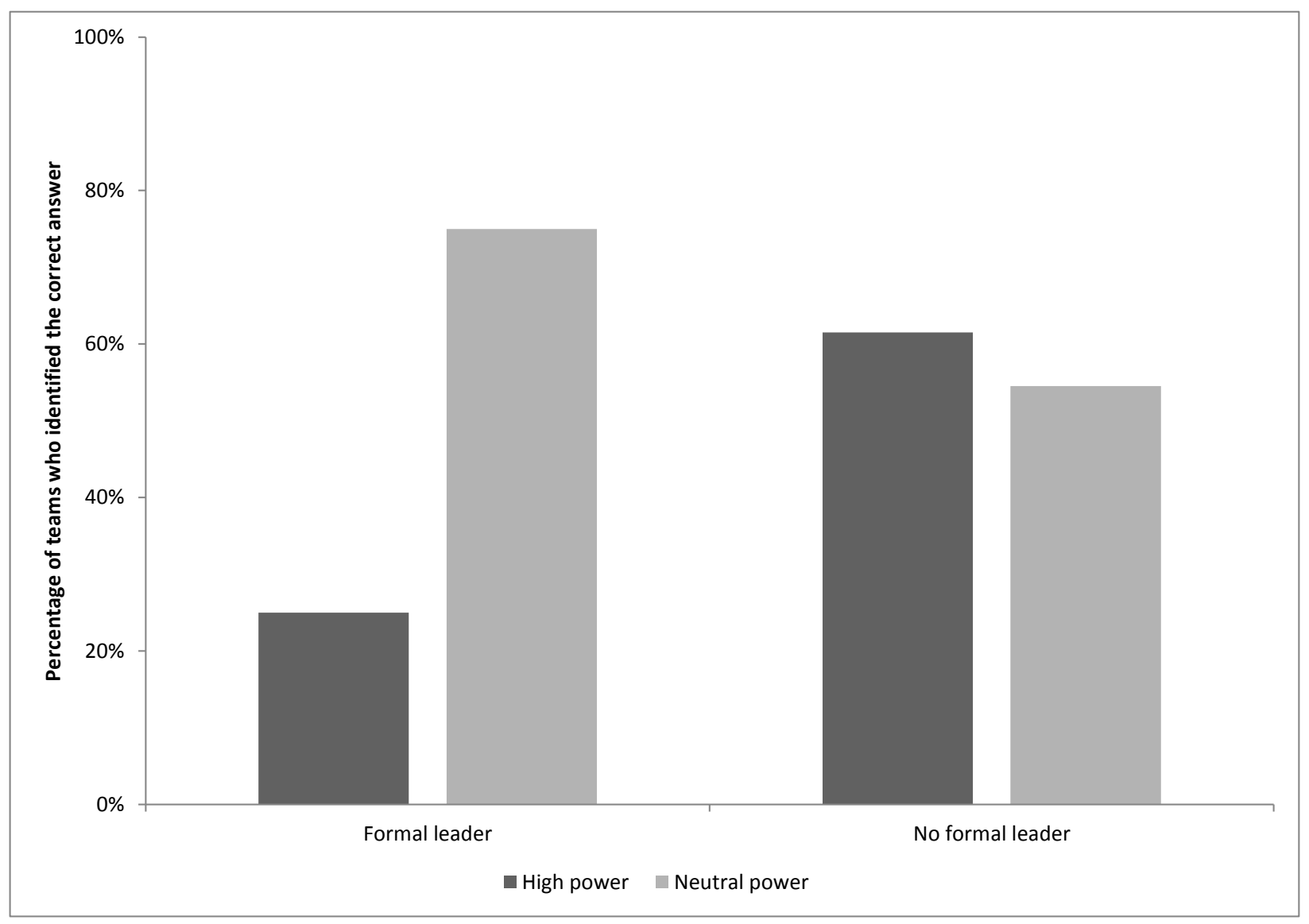


FIGURE 3

Team Performance, Study 3

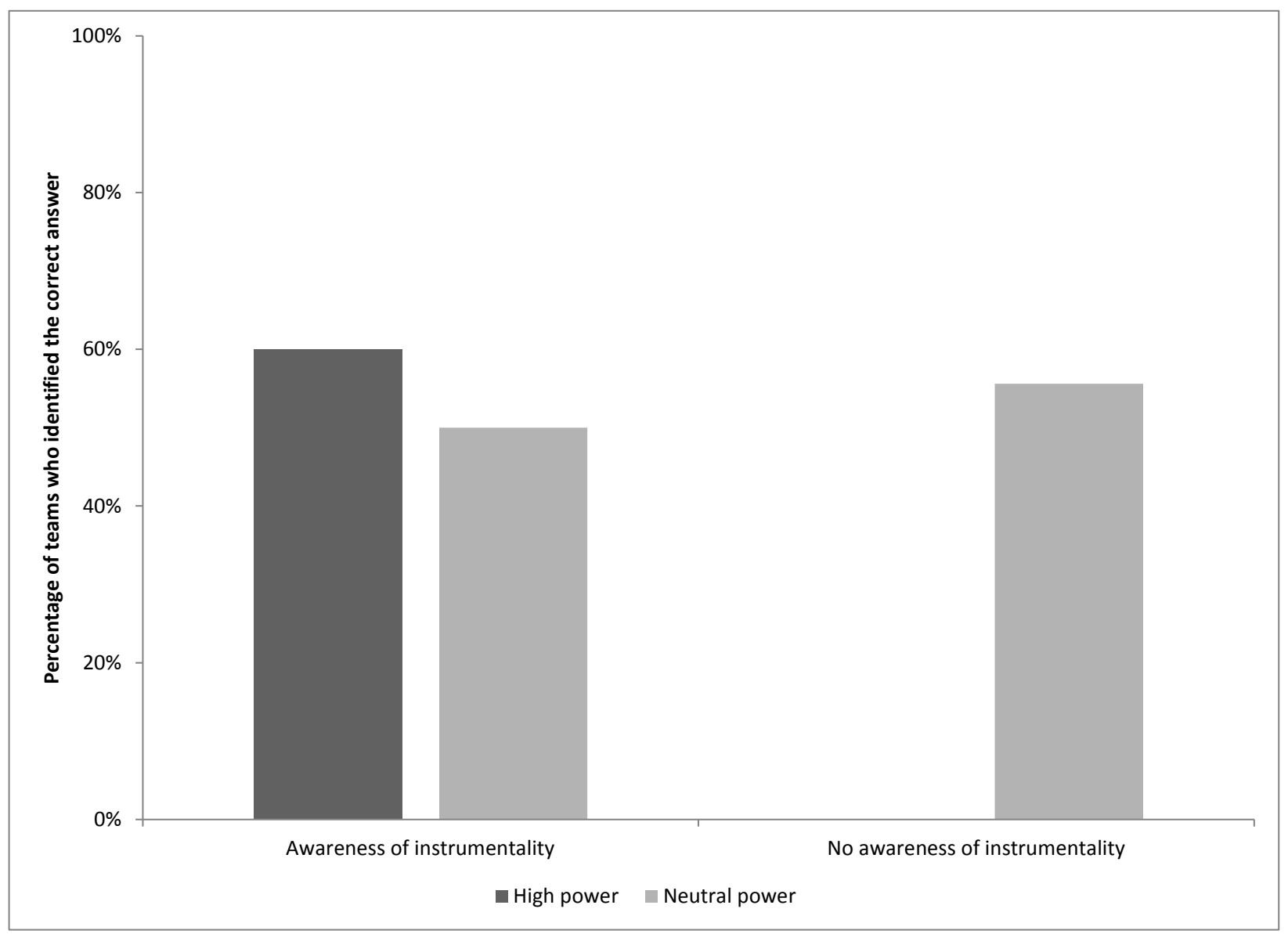


Leigh Plunkett Tost (lptost@umich.edu) is an assistant professor in the Management and Organizations Department at the University of Michigan's Ross School of Business. She received her Ph.D. from Duke University. Her research focuses on the psychological and sociological dynamics of power and status, as well as the motivations underlying individuals' pursuits of prosocial change.

Francesca Gino (fgino@hbs.edu) is an associate professor of business administration at Harvard Business School, Harvard University. She received her Ph.D. in economics and management from the Sant ${ }^{1}$ Anna School of Advanced Studies. Her research focuses on judgment and decision making, social influence, group dynamics, and ethics.

Richard P. Larrick (rick.larrick@duke.edu) is the Michael W. Krzyzewski University Professor in Leadership at Duke University's Fuqua School of Business. He received his Ph.D. from the University of Michigan. His research focuses on individual, group, and organizational cognition. 